\title{
The Teaching and Learning of Data-Handling in Primary Schools: South African Experience
}

\author{
Prof Emmanuel O. Adu PhD \\ Faculty of Education, University of Fort Hare, South Africa. \\ eadu@ufh.ac.za \\ Mr Lizo .J. Gosa \\ Faculty of Education, University of Fort Hare, South Africa. \\ lizogosa@yahoo.com
}

Doi:10.5901/mjss.2014.v5n23p814

\begin{abstract}
South Africa has achieved a lot in term of accessibility to education. According to the Consortium for Research on Educational Access, Transitions and Equity (CREATE, 2008), almost all children of school-going age (7 to 13 years) are enrolled in schools in South Africa. However, there are still some gaps between success and access in term of performance in some subjects especially mathematics. In fact the results of students in mathematics according to the Southern Eastern African Consortium for Monitoring Education Quality (SACMEQ) were of great concern. Therefore, the study explores some factors that affect the teaching and learning of data handling in mathematics at primary school. The study succinctly examines factors such as inability of the educators to explain and understand the curriculum according to Curriculum Assessment and Policy Statement (CAPS) that is, Pedagogical Content Knowledge (PCK); Subject Matter Knowledge (SMK) and Pedagogic Knowledge (PK), lack of qualified teachers to teach mathematic, lack of mathematics problem solving skills, language difficulties, inadequate statistical qualifications, and poor mastery of the prerequisite skills, fact and concepts. The study however, recommends among others that; the mathematics teachers should endeavour to identify what constitute challenges in mathematics. Especially in data handling oriented concepts, and devote more time to each of them in order to enhance students achievement, government needs to intensify teacher development to prepare educators for the implementation of the Curriculum and Assessment Policy Statement (CAPS) and pay special attention to the training of principals/educators
\end{abstract}

Keywords: Teaching and Learning, Data-Handling, Primary Schools, South African Experience

\section{Introduction}

In South Africa we have achieved the idea of success for all to education. This fact can be substantiated in the GET band ( General Education and Training band) phase ( Grade R to 9),where the gross enrolment ratio (GER) is 93\% (Shaughnessy,2007).Even ethnic minorities, have access to a complete free and compulsory primary education of good quality. This is a fact that can be proven through the focus on the access to primary education in South Africa. Primary education spans Grades 1 to 7. The appropriate age for primary schooling in South Africa is 7-to-13-year-olds. The Education Laws Amendment Bill of 2002 stipulates the age of admission to Grade 1 as the year in which a child turns 7 . However, a Constitutional Court challenge to the Bill in 2003, resulted in the school-going age for Grade 1 being changed to age 5, if a child turns 6 on or before 30 June in the Grade 1 year. This was implemented with effect from the 2004 school year and is still in place (Republic of South Africa, 1996b).

According to the Consortium for Research on Educational Access, Transitions and Equity (CREATE, 2008), almost all children of school-going age (7 to 13 years) are enrolled in schools in South Africa, with just under 2\% of learners never entering a public school. In 2005, the majority of learners stayed in school until the end of their primary schooling, with $89 \%$ completing Grade 7 . Repetition and drop-out rates are both calculated to reach an average of $4 \%$ during primary schooling, but these may be underestimates (CREATE, 2008).

The Statistics South Africa, national survey $2002-2009$ revealed that the participation of children aged 7 to 13 , in primary education by gender. The attendance of 7-to-13-year-olds remained high from 2002 to 2009. Overall, $99 \%$ of 7 to-13years olds were attending an education institution in 2009, compared to $96 \%$ in 2002. The increase between 2002 and 2009 constitutes 3\%.The GHS also indicates that attendance of learners by gender was almost equal for both 
females and males throughout the years, even though in 2007 and 2008 the Gender Parity Index (GPI) was standing at 0.99. Despite the progress cited above the results of the Southern Eastern African Consortium for Monitoring Education Quality paint a different picture (SACMEQ, 2011).

Mathematics is a language that makes use of symbols and notations to describe numerical, geometric and graphical relationships. It is a human activity that involves observing, representing and investigating patterns and quantitative relationships in physical and social phenomena and between mathematical objects themselves. It helps to develop mental processes that enhance logical and critical thinking, accuracy and problem-solving that will contribute in decision-making . The specific aim of mathematics is to develop:

- A critical awareness of how mathematical relationships are used in social, environmental, cultural and economic relations

- Confidence and competence to deal with any mathematical situation without being hindered by a fear of Mathematics

- An appreciation for the beauty and elegance of Mathematics

- A spirit of curiosity and a love for Mathematics

- Recognition that Mathematics is a creative part of human activity

- Deep conceptual understandings in order to make sense of Mathematics

- Acquisition of specific knowledge and skills necessary for:

- The application of Mathematics to physical, social and mathematical problems

- The study of related subject matter (e.g. other subjects)

- Further study in Mathematics. The teaching and learning of mathematics also hopes to:

- Develop essential mathematical skills the learner should

- develop the correct use of the language of Mathematics

- develop number vocabulary, number concept and calculation and Posing of questions for investigation

- Collecting, summarizing, representing and critically analysing data in order to interpret report and make predictions about situations

- Probability of outcomes include both single and compound events and their relative frequency in simple experiments (Department of Basic Education, 2011)

The SAQMEC Tests administered to students in 15 African countries, they indicated that South Africa 's grade 6 learners fare poorly in mathematics, when compared to learners of poorer countries such as Botswana, and Zimbabwe .The results for rural learners indicate that South Africa ranks 12 out of 15 for mathematics scores (Shaughnessy,2007). As it is understood that the teaching and learning of mathematics is a national and international problem .With the introduction of the National Curriculum Statement (NCS) in 2006, all the learners were required to do mathematics.

To further elucidate this fact (North \& Scheiber 2008) argued that through the advance in technology, a need for introduction of statistical literacy had become more essential. This resulted in statistics (Data-handling) forming integral part of both mathematics and mathematical literacy syllabi of NCS and Curriculum and Assessment Policy Statement (CAPS) which has been introduced in primary schools especially grade 7 in 2011. This called for the pupils to master the use of data from various contexts to make informed judgements (North \& Scheiber 2008).

In caps policy document, the purpose of data-handling is to enable the learners to develop skills to collect, organize, display, analyse, and interpret numeric data .In the senior phase the general concepts of data handling involve , asking questions and finding answers in order to describe events and the social, technological and economic environment.

Through the study of data handling, the learner develops the skills to collect, organize, represent, Interpret, analyse and report data, by:

- Posing of questions for investigation

- Collecting, summarizing, representing and critically analysing data in order to interpret report and make predictions about situations

- Probability of outcomes includes both single and compound events and their relative frequency in simple experiments. While these are the specific aims of teaching data handling in senior phase involve. The study of probability enables the learner to develop skills and techniques for making informed predictions, and describing randomness and uncertainty.

Progression in Data Handling is achieved primarily by:

- increasing complexity of data sets and contexts reading, interpreting and drawing new types of data graphs, becoming more efficient at organizing and summarizing data

- becoming more critical and aware of bias and manipulation in representing, analysing and reporting data 
- Learners should work through at least 1 data cycle for the year - this involves collecting and organizing, representing, analysing, summarizing, interpreting and reporting data. The data cycle provides the opportunity for doing projects.

- All of the above aspects of data handling should also be dealt with as discrete activities in order to consolidate concepts and practise skills. For example, learners need to practise summarizing data presented in different forms, and summaries should be used when reporting data.

- Data handling contexts should be selected to build awareness of social, economic and environmental issues.

- Learners should become sensitized to bias in the collection of data, as well as misrepresentation of data through the use of different scales and different measures of central tendency (mean, mode, median). Collect, organize and summarize data Collect data

- Pose questions relating to social, economic, and environmental issues in own environment

- Select appropriate sources for the collection of data (including peers, family, newspapers, books, magazines)

- Distinguish between samples and populations and suggest appropriate samples for investigation

- Design and use simple questionnaires to answer questions:

- With yes/no type responses with multiple choice responses. Organize and summarize data

- Organize (including grouping where appropriate) and record data using tally mark- tables stem-and-leaf displays

- Group data into intervals

- Summarize and distinguishing between ungrouped numerical data by determining:

- mean, median, mode

- Identify the largest and smallest scores in a data set and determine the difference between them in order to determine the spread of the data (range). Represent data to

- Draw a variety of graphs by hand/technology to display and interpret data (grouped and ungrouped) including: bar graphs and double bar graphs, histograms with given intervals, pie charts.

- Critically read and interpret data represented in: words bar graphs, double bar graphs, pie charts histograms

- Critically analyse data by answering questions related to: data categories, including data intervals, data sources and contexts central tendencies (mean, mode, median) scales used on graphs.

- Summarize data in short paragraphs that include

- drawing conclusions about the data

- making predictions based on the data

- identifying sources of error and bias in the data

- Choosing appropriate summary statistics for the data (mean, median, mode)

- The following resources provide interesting contexts for data comparison and analysis that can be used in this phase (senior phase):

- Census at School - for school based surveys national surveys from Statistics South Africa (StatsSA) - for household and population surveys. International surveys from United Nations (UN Data) - for international social, demographic and environmental surveys. Many other websites may be consulted, especially for health and environmental data (Department of Basic Education, 2011).

This development comes against the backdrop that in the past(post-Apartheid curriculum) statistics in South African Mathematics curriculum in the primary schools was reduced to tasks in which learners were given graphs about which simple direct questions had to be answered. Likewise the mean, median, and mode (measures of central tendency) of small data sets had to be determined according to prescribed formulas, without real understanding from the teacher's or learner's side of the role and appropriateness of and differences between these measures of central tendency (Wessels, 2008). The revelation of the study surprised the teachers as they recalled that their learners were very responsive and enthusiastic when this section of the work was covered in class. The researcher viewed that some of the reasons that might impacted negatively to teaching and learning is the education system prior in 1995. Education in South Africa during the apartheid era (before 1995) was differentiated with the existence of racially separate education departments. The Bantu Education Act (Act No. 47 of 1953) intended to separate black South Africans from the main, comparatively very well-resourced education system for whites. The quality of education offered to the black learners was of an inferior quality and lacked effectiveness, and black schools had inferior facilities, teachers and textbooks (Mason et. al. 2011)

Despite numerous government interventions and policy changes, poor quality of teaching and learning seem to form part of the challenges in mathematics. Data-handling which is one of the newly introduced strands in school mathematics seems to form part of the challenges. These challenges require different approaches from both teachers 
and learners to overcome them. These can include a range of challenges such as, if the teacher has not studied statistics as his or her mathematics course, or indeed if the teacher was not a subject specialist (Stohl, 2005).Mathematics is viewed by scholars as abstract science of numbers, quantity and space either as abstract concepts (pure mathematics) or as applied in other disciplines such as physics, and engineering (applied mathematics). The dissimilarity between mathematics and mathematical literacy is the concept, the complexity and the fact that mathematical literacy is more contextual whereas mathematics in more abstract (Stohl, 2005).

\section{Rationale for the Study}

From the aforementioned background, it is proved by different scholars and researches have shown that the data handling in mathematics seemed to cause poor performance in mathematics. Therefore, the study concisely investigates some factors that affect teaching and learning of data handling in primary schools in South Africa.

\section{Factors Affecting Teaching and Learning of Mathematics in South Africa}

In South Africa the teaching of mathematics seems to experience major challenges confronting educators which are the lack of qualified teachers in the teaching of mathematics, particularly in statistics mostly in rural schools. The teaching of mathematics does not only require the teacher to have knowledge about the topic to be taught, the teacher has to be proficient in solving any problem within the topic. The teacher must be able to use mathematical knowledge to select and clarify the appropriate mathematical goals for any lesson taught (Stohl, 2005). A mathematics teacher must be able to sequence mathematical tasks into appropriate lesson designs and also be able to interpret curriculum materials and explain to learners . The teacher must be able on the spot to evaluate learners explanation of mathematical worth. (Stohl, 2005) view this as task of mathematical problem solving that needs to be done in teaching. They suggest that it is productive to think about the kind of mathematical work done by teachers to problem solving enacted in the practice of teaching.

The notion of mathematical work as being used to describe the mathematical reflection, focusing on the mathematics the teacher draws on to accomplish the tasks. Stohl (2005) argued that Shulman views the notion of pedagogical content knowledge (PCK) as the blending of the subject matter knowledge and pedagogic knowledge and distinguishes this knowledge from what he calls" subject matter knowledge". he also suggested that Bell and coresearchers in mathematics, view detailed knowledge as entailing being able to unpack or decompress mathematical ideas so that they can be accessible to learners. In order to understand the teachers in South Africa who continue to teach in the system after the dismantling of apartheid, it is important to have a clear understanding of the education system and teacher training system leading up to the 1990s. The researcher tried to give a brief review thereof, but before that the researcher tried to highlight the importance of primary education. It forms the basis for preparation of learners for secondary education. The role of education on shaping our lives cannot be underestimated (Lumeta \& Makonye, 2010). There is no single person who can claim that primary education had no influence in his or her life. The fact that one can remember something significant that happened to him or her whilst at school is a good retention. The strength of these memories is an indication of the importance that those years in primary school held for us as individuals (Lumeta \& Makonye, 2010)

\section{Factors Affecting Teaching and Learning of Data Handling}

\subsection{Factors due to language difficulties}

In solving word problems learners should be familiar with the language used in mathematical concepts, symbols, and vocabulary. A misunderstanding of semantics of mathematical text could often be a source of pupil's factors. The researcher therefore interrogated this form of factor and its significant impact. Mathematics is seen as an important subject that leads to the development of other scientific fields. Mathematics education begins in language, it advances and stumbles because of language, and its outcomes are often assessed in language (White, 2011). Language is critical for cognitive development as it provides the concepts for thinking and therefore a means for expressing ideas and asking questions (Vygotsky, 1989). In agreement with this view, it has been argued that we use words to construct our interpretation of experience; that our experiences shape our language; and in the culture of schools a concept does not exist until it has been named and its meaning shared with others (Kazima \& Adler, 2008). 


\subsection{Educator factors due to inadequate statistical qualifications}

The research looked at what do mathematics teachers need to know and be able to do practice in order to teach datahandling at senior phase. In trying to answer this question, there had to be three inter-related questions that are explored which were what aspects of data-handling were encoded in the curriculum document? What mathematical problem solving challenges did teachers face as they went about teaching data-handling in their classrooms? What knowledge resources did teachers draw on as they did what they did? (Kazima, 2008). 50\% of mathematics teachers in South Africa have no formal qualifications in mathematics (Menoe, 2005).

The situation is so because black colleges of education earlier known as teacher training colleges, were established in accordance with Verwoerd vision. "What is the use of teaching Bantu child mathematics when it cannot use it in life"? That is absurd (Menoe, 2005). They had inferior and separate curriculum from their counterparts who belonged to other races. Mathematics teachers in these colleges were mainly white Afrikaners who in most cases were not adequately qualified to teach mathematics in their own schools .Black academic staff taught vernacular only and the majority were unskilled labourers. Hence mathematics teacher educators had little understanding of black schools, the lives of teachers and their plight.

They had little concern and / or ability to improve mathematics teaching practice as this would undermine the rules and the system today. With the change politically in the nineties, black trainers were introduced into colleges but curriculum still centrally controlled. The quality of mathematics education in the majority of colleges was such that their graduate teachers were under-prepared to teach mathematics effectively. Hence the regular high rate of failure for black grade12 in mathematics, Children of that era were prevented from receiving an education in keeping with the advances of the twentieth century. Though Apartheid was abolished in 1994,the after effects of the deprivation of the majority of citizens in South Africa continues to the mathematics education of black schools children from 50s to the early $90 \mathrm{~s}$, has resulted in critical shortage of mathematics teachers even today. We are using the term 'mathematics for teaching' (MfT) to refer to 'specialised Mathematical knowledge that teachers (need to) know and know how to use it in their teaching'.

\subsection{Factors due to mastery of prerequisite skills, facts, and concepts}

Deficit in basic pre-requisites include ignorance of algorithms, inadequate mastery of basic facts, incorrect procedures in applying mathematical techniques and lack of sufficient knowledge of necessary concepts and symbols. The researcher will explore this factor and its significant importance. First and fore most the study looked at the achievements and teacher needs in terms statistics strand. To achieve this, the study tried to look at deficit in basic skills, like the algorithms and the mastery of the application of mathematical procedures and mathematical techniques. There were two significant developments in education provided (a) the new general interest in teacher professionalism and the accompanying calls for criteria to assess teacher competence and (b)The changes within the mathematics curriculum itself. Associated with these changes was the need to assess teacher's current levels of competence for the purposes of ensuring continued professionalism and suggesting professional development programmes for improving performance.

The question aroused whether a single instrument could satisfy the requirements of both demonstrating teacher professional competence and indicating aspects of performance that required further development. If teacher professionalism was to be meaningful goal in a constantly changing educational milieu, then both aspects of teacher practice should have been acknowledged. The profiling instrument presented hare was developed to address the issue of teacher competence and curriculum change in relation to the reform of the mathematics curriculum in the $1990 \mathrm{~s}$

\section{Conclusion/Recommendations}

The study seeks to determine the factors affecting the teaching and learning of data handling. Some of the factors identified include inability of the educators to explain and understand the curriculum according to Curriculum Assessment and Policy Statement (CAPS) vis; Pedagogical Content Knowledge (PCK); Subject Matter Knowledge (SMK) and Pedagogic Knowledge (PK), lack of qualified teachers to teach mathematic, lack of mathematics problem solving skills, language difficulties, inadequate statistical qualifications, and poor mastery of the prerequisite skills, fact and concepts. The in-service training of teacher training through distant learning did not show much assistance. This was due to distance of schools for visits by mentors in rural areas. The mathematics teachers should endeavour to identify what constitute challenges in mathematics. Especially in data handling oriented concepts, and devote more time to each of them in order to enhance students achievement.

As a country and as the continent government need to intensify teacher development to prepare educators for the 
implementation of the Curriculum and Assessment Policy Statement (CAPS) and pay special attention to the training of principals, particularly those in underperforming schools. In terms of learner support material In line with the call made by President Jacob Zuma in the 2011 State of the Nation Address emphasising the need for more focus on the Triple T Teachers, Text and Time - we will double our efforts on the Provision of high-quality workbooks in literacy and numeracy to Grades 1-6 learners and numeracy and life skills to Grade R learners. We will also focus on providing a textbook for every learner in every subject. Annual National Assessments must be conducted in literacy and numeracy that is internationally bench marked.

In terms of District development government should strengthen district support and development and improve intervention at class level so as to promote the quality of teaching and learning. To achieve quality education we need to ensure the provision of sound infrastructure. This priority focuses on the need to guarantee that learners and teachers are able to function in an enabling physical and physiological (health and welfare) environment.

The main goal is to eradicate mud and unsafe structures and to provide improved resources, such as laboratories, libraries and administration blocks to existing schools . The Department commits itself to the delivery of the targets set out in the Action Plan and to strengthening reporting on the state of basic education. This will be done through the publication of frequent reports flowing from the monitoring and research work of the Department, and in particular, the publication of an annual report on the state of the basic education sector.

\section{References}

CREATE (2008) .Educational access in South Africa: Country Policy Brief .Johannesburg Department of Basic Education (2011).Intermediate phase policy document. Pretoria, South Africa

Kazima, M \& Adler, J. (2008): Mathematics for teaching: Observations from two case studies South Africa Journal of Education: Vol. 28: 283-299

Lumeta, K \& Makonye P.J. (2010). Learners' errors and misconceptions in elementary analysis: A case of Grade 12 class in South Africa. Act Didacica Napocensia.3 (3)

Mason B.J., Patry, M. \& Bernstein, D.J. (2011). An examination of the equivalence between non-adaptive computers based test and traditional testing. Journal of Educational Computing Research, 24, 29-39.

Menoe, J.M. (2005). Dealing with mixed abilities in standard grade Mathematics classes in South Africa. Universiteit Twente. The Netherlands, ENSCHEDE

North, D. \& Scheiber, J. (2008). Introducing statistics at school level in South Africa: The crucial role played by the national Statistics Office in training in-service teachers. In C. Batanero, G. Burrill, C. Reading, \& A. Rossman (Eds.), Proceedings of the 18th ICMI Study Conference and 2008 IASE Round Table Conference

Shaughnessy, J.M. (2007). Research on statistics learning and reasoning. In F.K. Lester (Ed.), Second handbook of research on mathematics teaching and learning (pp.957-1009), NC: National Council of Teachers of Mathematics Charlotte

Southern Eastern African Consortium for Monitoring Education Quality SACMEQ (2011). General Household Survey Interactive Data sets .Pretoria: Stats S.A.

Stohl, H. (2005) Probability in teacher education and development. In G. Jones (Ed) exploring probability in schools: challenges for teaching and learning (pp. 345-366). New York. Springer

Vygotsky, L. (1989). Thought and Language. Newly revised and edited by Kozulin Massachusetts Institute of Technology .Holliday Lithography.

Wessels, H.M. (2008). Types and levels of data arrangement and representation in statistics as modelled by grade 4 to 7 learners. Unpublished doctoral dissertation. University of South Africa, Pretoria, South Africa. Available from http://hdll.handle.net/10500 11867

White, A.L. (2010). Numeracy, Literacy and Newman's Error Analysis: Journal of Science and Mathematics Education in Southeast Asia, 33 (2), 129-148 